\title{
ANALISIS TEGANGAN DAN ARUS PADA PERANCANGAN ARESTER KASKADE
}

\author{
Hanifiyah Darna Fidya Amaral ${ }^{*}$, Wijono, Harry Soekotjo Dachlan \\ Jurusan Teknik Elektro, Universitas Brawijaya Malang \\ Jl. Veteran, Malang 65145 INDONESIA \\ ${ }^{*}$ E-mail: hanifiyahamaral@gmail.com
}

\begin{abstract}
Abstrak
Arester merupakan komponen perlindungan tegangan lebih yang dipasang pada sebuah peralatan listrik. Arester dapat digunakan secara individu maupun gabungan dari jenis arester yang berbeda. Penggabungan dua jenis arester yang berbeda dapat dilakukan secara kaskade. Pada makalah ini dilakukan perancangan arester kaskade dengan menggabungkan komponen MOV dan GDT. GDT dirancang pada stage pertama dan MOV pada stage kedua dikarenakan GDT memiliki tegangan kerja lebih tinggi daripada MOV. Arester kaskade dapat berkoordinasi dengan baik apabila arester yang memiliki tegangan kerja lebih tinggi terletak di bagian depan dan tegangan kerja yang lebih rendah diletakkan di bagian belakang. Sehingga GDT dirancang pada stage pertama dan MOV pada stage kedua. Rangkaian arester kaskade berhasil dilakukan dengan dekopling induktor. Simulasi surja juga berhasil dilakukan dengan menggunakan generator impuls. Tegangan surja disimulasikan oleh generator impuls menghasilkan nilai sebesar 920V dengan rise time 1,2 $\mu$ s, berdurasi $50 \mu \mathrm{s}$. Simulasi arus surja juga berhasil dilakukan dengan menghasilkan arus sebesar $470 \mathrm{~A}$ dengan rise time $8 \mu \mathrm{s}$, berdurasi $20 \mu \mathrm{s}$. Gelombang arus dan tegangan potong pada GDT telah berhasil dilakukan dengan simulasi. Nilai dekopling induktor yang berbeda juga mempengaruhi nilai arus yang mengalir pada MOV sehingga energi yang mengalir pada peralatan listrik yang diproteksi menjadi lebih rendah. Peningkatan nilai dekopling induktor memberikan distribusi energi yang tepat antara arester GDT dan MOV.
\end{abstract}

Kata kunci:arester, araster kaskade, metal oxide varistor (MOV), gas discharge tube (GDT), tegangan tinggi, distribusi energi

\begin{abstract}
An arrester is an overvoltage protection component mounted on an electrical equipment. Arresters can be used individually or a combination of different types of arresters. Combining two different types of arresters can be done in a cascade. In this paper the arrester cascade is designed by combining MOV and GDT components. GDT is designed on the first stage and MOV in the second stage because GDT has a higher working voltage than MOV. The arrester cascade can coordinate well if the arrester has a higher working voltage located at the front and a lower working voltage is placed at the rear. So that GDT was designed in the first stage and MOV in the second stage. The arrester cascade circuit was successfully carried out by inductor decoupling. The surge simulation is also successfully carried out using an impulse generator. The surge voltage simulated by an impulse generator produces a value of $920 \mathrm{~V}$ with rise time $1.2 \mu \mathrm{s}$, with a duration of $50 \mu \mathrm{s}$. The simulation of surge current was also successfully carried out by producing a current of $470 \mathrm{~A}$ with rise time $8 \mu \mathrm{s}$, duration of $20 \mu \mathrm{s}$. The current wave and cut voltage on GDT have been successfully carried out by simulation. Different inductor decoupling values also affect the value of current flowing on the MOV so that the energy flowing on the protected electrical equipment becomes lower. Increasing the value of the inductor decoupling provides the right energy distribution between the GDT arrester and MOV.
\end{abstract}

Keywords: arrester, cascade arrester, metal oxide varistor (MOV), gas discharge tube (GDT), high voltage, energy distribution

\section{Pendahuluan}

Petir merupakan fenomena alam berenergi sangat tinggi yang dapat menjadi sumber berbahaya. [1]. Serangan kilat ke objek atau sistem yang tidak dilindungi dapat menjadi bencana. [2]. Oleh karena itu, diperlukan peralatan perlindungan tegangan lebih dari serangan petir mendadak. Sistem perlindungan tegangan lebih harus dirancang untuk menangkap pelepasan atmosfer ke titik yang lebih disukai, membawa energi ke dalam tanah dan melindungi semua daya yang masuk dan jalur komunikasi menggunakan perangkat surge protective devices (SPD). [3]. Perangkat SPD memiliki dua tugas utama yang harus dipenuhi, yaitu: 
pertama, untuk mengalihkan sejumlah besar energi gelombang ke tanah (yang mengacu pada kemampuan penyerapan energi SPD), dan kedua, untuk menjepit tegangan lonjakan ke tingkat di bawahnya untuk menahan tingkat tegangan impuls perangkat yang dilindungi.[4].

Perlindungan dengan tegangan yang lebih tinggi mempengaruhi kemampuan penyerapan energi yang relatif tinggi juga pada sebuah perangkat SPD. Perlindungan satu tahap (one-stage) SPD pada pintu masuk layanan hampir tidak dapat memberikan karakteristik perlindungan yang memadai. [5]. Selain kemampuan tersebut, permasalahan tentang jarak perlindungan yang efektif dari pemasangan SPD mungkin dipertanyakan. [6], [7], [8], [9]. Sehingga dapat ditemukan solusi dari kondisi tersebut ialah menerapkan perangkat kaskade SPD dengan sistem perlindungan dua tahap. Perlindungan peralatan yang tepat terhadap calon surja dapat dilakukan dengan memilih karakteristik SPD dan memperhatikan lokasi dalam rangkaian dengan tepat. Terutama untuk peralatan sensitif. [4].

Arester kaskade dapat berkoordinasi dengan baik apabila arester yang memiliki tegangan kerja lebih tinggi terletak dibagian depan dan tegangan kerja yang lebih rendah dan di bagian belakang. Oleh karena itu, penelitian ini menggabungkan dua buah arester tegangan rendah yaitu GDT (Gas Discharge Tube arrester) dan MOV (Metal Oxide Varistor) secara kaskade. GDT merupakan arester tipe switching, sedangkan MOV merupakan arester tipe clamping. [10].

GDT adalah tabung keramik dengan dua elektroda yang dimasukkan di dalamnya dan diisi dengan gas tertentu (gas mulia, seperti Ar, $\mathrm{Ne}$, atau campuran keduanya). Komponen switching tegangan ini beroperasi dengan beralih dari kondisi resistansi tinggi ke rendah pada tegangan gangguan tertentu dan berperilaku sebagai korsleting. [3]. Sedangkan MOV terbuat dari campuran zinc oxide dan metal oxide lainnya seperti cobalt, mangan dan lainnya. MOV akan mulai konduksi pada spesifik tegangan tertentu dan akan berhenti konduksi ketika tegangannya jatuh dibawah tegangan kerjanya.

Pada makalah ini dirancang arester kaskade dengan komponen GDT dan MOV. Arester kaskade dapat berkoordinasi dengan baik apabila arester yang memiliki tegangan kerja lebih tinggi terletak dibagian depan dan tegangan kerja yang lebih rendah diletakkan di bagian belakang. Sehingga GDT dirancang pada stage pertama dan MOV pada stage kedua. GDT dapat memotong gelombang tegangan lebih hingga puluhan volt dan kemampuan penanganan energi yang besar. Sedangkan MOV, dapat membatasi tegangan secara konstan dan kemampuan penanganan energi yang kecil. [10]. Arester kaskade dirancang berdasarkan distribusi energi surja. arester kaskade pada penelitian ini menggunakan dekopling induktor. Analisis distribusi energi dilakukan karena GDT dan MOV memiliki karakteristik yang berbeda dalam memotong tegangan dan penanganan energi surja. Profil tegangan dan arus GDT dan MOV dianalisis sehingga akan menghasilkan nilai energinya.

\section{Metode}

Pada artikel ini dirancang arester kaskade berdasarkan distribusi energi surja. Komponen arester kaskade menggunakan arester tegangan rendah GDT dan MOV serta sebuah dekopling induktor. Bentuk dari arester GDT dan arester MOV ditunjukkan pada gambar 1 (a) dan 1 (b) dibawah ini.

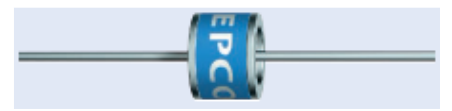

(a)

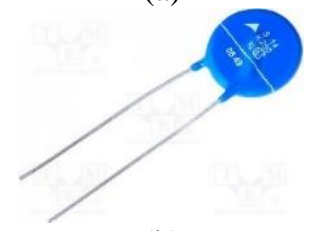

(b)

Gambar 1. Arester tegangan rendah (a) Gas Discharge Tube, (b) Metal Oxide Varistor

Pada penelitian ini komponen GDT yang digunakan ialah GDT EPCOS tipe A71-H10X DC. GDT adalah salah satu elemen penting untuk proteksi tegangan lebih pada tegangan rendah (LV), terhadap dampak berbahaya dari tegangan lebih yang disebabkan oleh fenomena atmosfer. [11]. GDT merupakan salah satu komponen proteksi surja primer. GDT terbuat dari tabung keramik tertutup dengan dua elektroda yang dimasukkan di dalamnya dan diisi dengan gas tertentu (gas mulia, seperti Ar, Ne, atau campuran keduanya). Elektroda - elektroda dipisahkan oleh gap, dimana discharge terjadi. [12]. GDT adalah perangkat paling populer yang digunkan untuk saluran telekomunikasi, jaringan sinyal, atau perangkat, dan jaringan listrik dari proteksi surja. Banyak GDT digunakan pada aplikasi tersebut karena dapat menangani lonjakan arus setinggi $10 \mathrm{kA}, 8 / 20$, lebih jauh tergantung pada desain dan ukuran GDT. [13] [14]. Selama operasi normal pada tegangan normal, GDT berperilaku sebagai isolator. [2]. Ketika ada tegangan sparkover (diatas tegangan kerjanya), akan terjadi electrical breakdown dalam tabung dan terjadi transisi glow region ke arc region yang ditunjukkan pada gambar 2. [2].

GDT EPCOS tipe A71-H10X DC berbahan keramik dengan karakteristik kapasitansi yang rendah dan memiliki resistansi isolasi yang tinggi lebih dari $10 \mathrm{G} \Omega$. GDT tipe ini memiliki tegangan rata-rata spark-over DC sebesar $800 \mathrm{~V}$. 


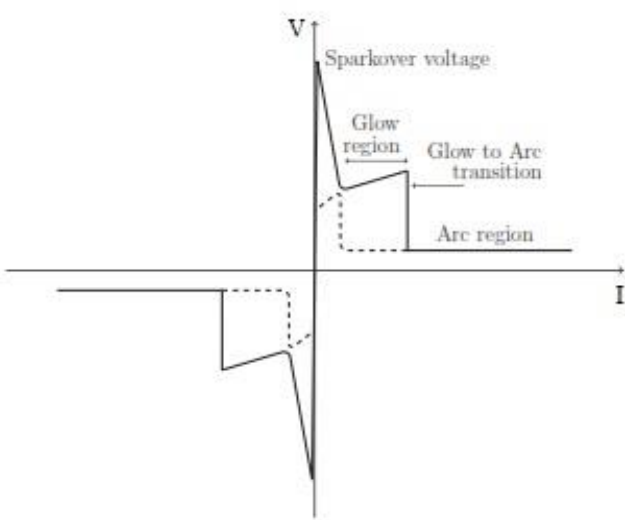

Gambar 2. Karakteristik V - I GDT.[3]

Komponen selanjutnya yang digunakan pada rangkaian arester kaskade adalah MOV. MOV merupakan salah satu komponen pelindung surja sekunder. MOV merupakan resistor dengan karakteristik V-I tidak linear. [3]. MOV terdiri dari butiran zinc oxide dengan sejumlah kecil zat adiktif metal oxide yang dipilih dengan cermat $\left(\mathrm{Bi}_{2} \mathrm{O}_{3}\right.$, $\mathrm{MnO}, \mathrm{Cr}_{2} \mathrm{O}_{3}, \mathrm{Sb}_{2} \mathrm{O}_{3}$ ) yang dipadatkan untuk meningkatkan V - I tidak linear. [15]. Karakteristik V - I MOV dapat kita lihat pada gambar 3. MOV memiliki karakteristik bidirectional simetris, sehingga varistor beroperasi di dua wilayah (kuadran I dan III) dari gelombang sinusoidal seperti perilaku dua dioda zener terhubung back-to-back. [16]. Ketika tidak konduksi, kurva V - I menunjukkan hubungan yang linear seperti arus yang mengalir melalui varistor tetap konstan dan rendah saat beberapa mikroampere dari kebocoran arus. Hal ini dikarenakan resistensi tingginya seperti rangkaian terbuka dan akan tetap konstan sampai tegangan yang melewati MOV mencapai tegangan kerjanya.

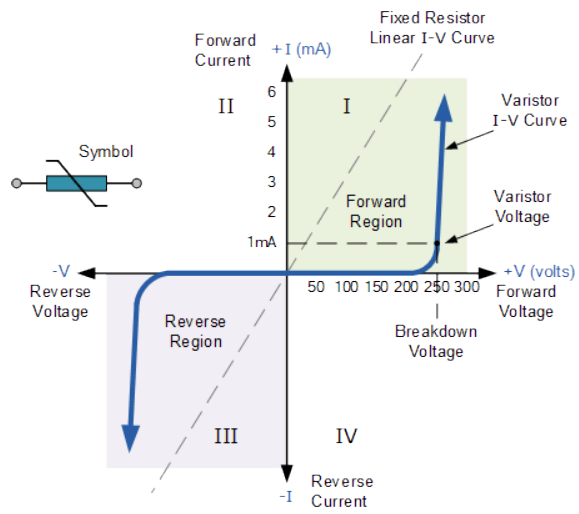

Gambar 3. Karakteristik V - I dari MOV.[4]

MOV yang digunakan pada penelitian ini adalah merk littelfuse yaitu MOV dengan tipe dasar $\mathrm{ZnO}$ varistor berbentuk disc (bulat). MOV ini memiliki tegangan nominal dan arus discharge yang tinggi sebesar $470 \mathrm{~V}$ dan 4000 A. Kecepatan respon yang dimiliki MOV tipe ini juga sangat cepat dibawah 50 nanosekon.
Profil tegangan dan arus keluaran pada arester kaskade akan diukur dan dianalisis. Nilai energi dari arester GDT dan MOV digunakan dalam menghitung impedansi dekopling induktor. Rangkaian arester kaskade secara jelas ditunjukkan pada gambar 4.

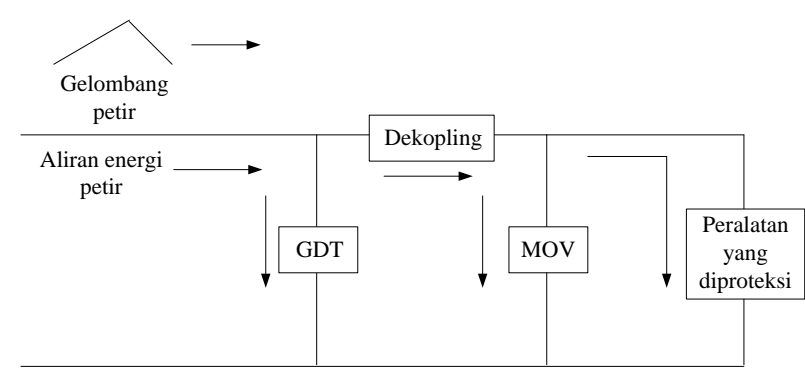

Gambar 4. Aliran energi arester kaskade GDT dan MOV

Simulasi rangkaian arester kaskade dilakukan pada perangkat lunak LTSpice IV. Rangkaian simulasi pertama yang dirancang adalah rangkaian generator impuls untuk digunakan sebagai simulasi tegangan dan arus surja. Rangkaian simulasi generator impuls RLC pada gambar 5.

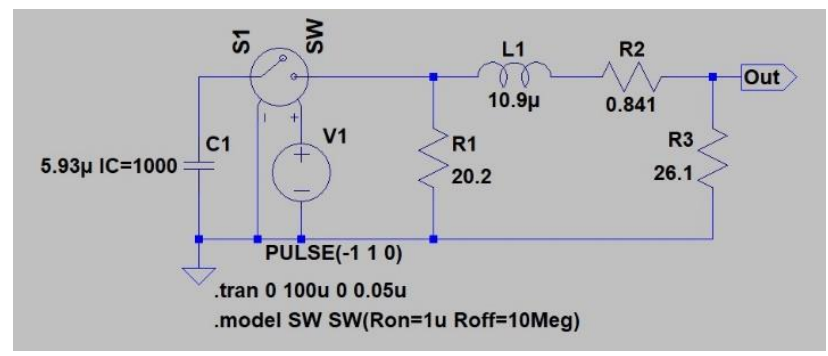

Gambar 5. Rangkaian Generator Impuls

Rangkaian generator impuls yang digunakan dalam simulasi tegangan dan arus surja terdiri komponen switching, kapasitor, induktor dan resistor. Switch (SW1) yang digunakan adalah tipe voltage controlled switch. SW1 digunakan sebagai penganti spark gap yang akan menghasilkan percikan api (spark-over) dari surja. Percikan api (spark-over) terjadi pada waktu tegangan mencapai suatu harga tertentu. Kapasitor C1 merupakan kapasitor discharge yang melepaskan muatan melalui resistor dan induktor.[17]. R1 merupakan tahanan peredam (damping resistance) yang dipasang untuk menghindari osilasi berfrekuensi tinggi. $\mathrm{R}$ yang lain dan $\mathrm{L}$ digunakan untuk mengatur bentuk gelombang yang dihasilkan sehingga menyerupai profil surja.

Nilai kapasitor $\mathrm{C} 1$ telah terisi penguatan tegangan IC (initial condition) $1000 \mathrm{~V}$. Nilai kapasitansi kapasitor C1 diperoleh dari persamaan :

$C 1=2 W\left(\frac{\eta}{V_{\text {maks }}}\right)^{2}$ 
Sedangkan nilai L1 diperoleh degan persamaan :

$$
L 1=\frac{1}{C\left(\gamma^{2}-\delta^{2}\right)}
$$

Nilai R2 dan R3 diperoleh dari persamaan :

$$
\begin{aligned}
& R 2=\frac{2 \gamma}{C\left(\gamma^{2}-\delta^{2}\right)} \\
& R 3=\frac{\eta R \delta}{\gamma\left(e^{\frac{1}{1-b} \ln b}-e^{\frac{b}{1-b} \ln b}\right)}
\end{aligned}
$$

Rangkaian simulasi kedua adalah rangkaian kaskade arester GDT dan MOV. Rangkaian kaskade arester GDT dan MOV menggunakan dekopling induktor. Gambar rangkaian dapat dilihat pada gambar 6.

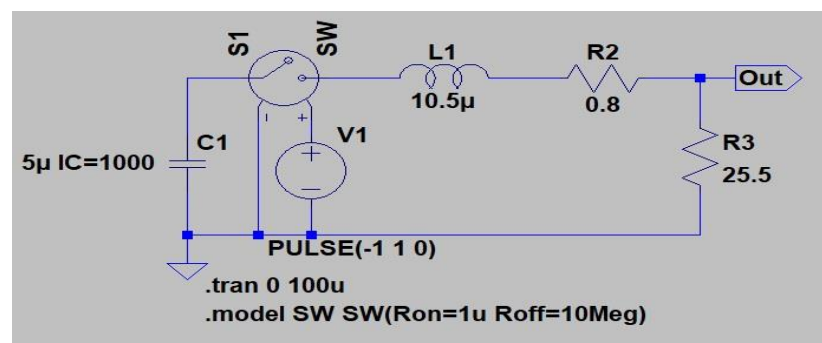

\section{Gambar 6. Arester kaskade GDT dan MOV}

Rangkaian arester kaskade terdiri dari rangkaian generator impuls, rangkaian ekivalen GDT dan sebuah MOV. Rangkaian ekivalen GDT dirancang menyerupai karakteristik dari GDT menggunakan komponen R5, C2, SW2 (Voltage Controlled Switch) dan R6. Gelombang implus melalui R5 dan C2 kemudian switch SW2 bekerja berdasarkan triger tegangan pulse V2. Ketika switch SW2 bekerja, maka terjadi pemotongan tegangan impuls (tegangan sisa). Pada fase ini GDT memasuki glow to arc region yang sesuai dengan karakteristik GDT pada gambar 2. Resistor R6 sebagai penahan tegangan GDT dari spark over menuju arc region agar tidak sampai menuju tegangan nol volt. Sedangkan komponen MOV pada rangkaian ditunjukkan pada komponen A1 (MOV), V3 dan R4. L2 pada rangkaian merupakan dekopling induktor antara GDT dan MOV.

\section{Hasil dan Analisa}

Hasil dari simulasi diukur dan diamati. Terdapat tiga bagian yang diukur dan diamati. Yaitu output generator impuls dalam keadaan open circuit dan short circuit, profil tegangan dan arus GDT, dan profil tegangan dan arus MOV ketika dekopling.

\subsection{Generator Impuls pada Kondisi Open Circuit dan Short Circuit}

Berdasarkan gambar 5 rangkaian generator impuls mulai bekerja ketika kapasitor $\mathrm{C} 1$ sudah termuati oleh sumber tegangan DC dengan nilai tegangan $1.04 \mathrm{kV}$. Ketika saklar
S1 ditutup maka akan mengalir energi dalam rangkaian $\mathrm{R}$ dan L. Gambar 7 menunjukkan gelombang impuls memiliki puncak tegangan ketika open circuit hingga 920V dengan rise time $1,2 \mu \mathrm{s}$ dan durasi 50 4 s. Gambar 8 menunjukkan gelombang impuls dengan puncak arus ketika short circuit hingga 470A dengan rise time $8 \mu$ s dan durasi $20 \mu \mathrm{s}$.

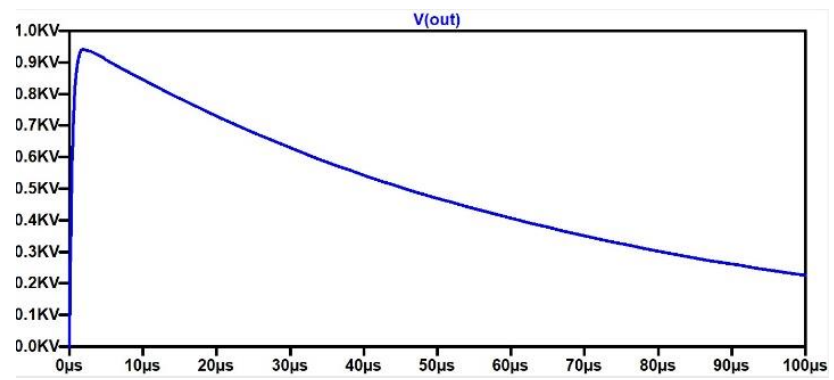

Gambar 7. Gelombang Tegangan Open Circuit

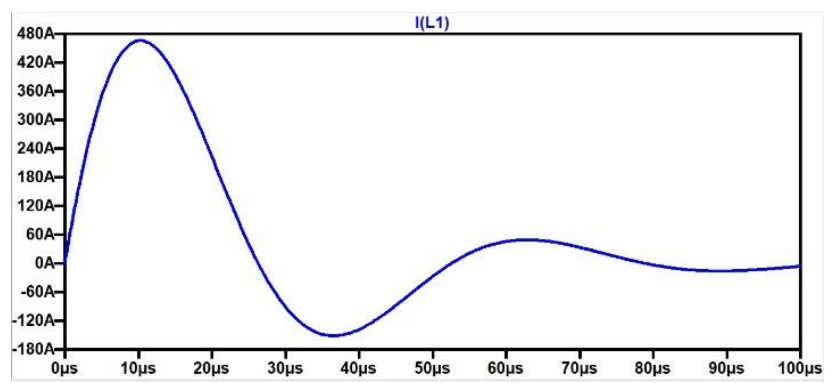

Gambar 8. Gelombang Arus Short Circuit

Rangkaian kaskade arester GDT dan MOV yang ditunjukkan pada gambar 6 diuji dengan menggunakan tegangan impuls $1,2 / 50 \mu$ s. Dekopling induktor (L2) yang digunakan pada rangkaian kaskade arester GDT dan MOV dibuat bervariasi dengan nilai $1 \mathrm{mH}$ dan $1 \mathrm{H}$ untuk mengetahui distribusi energi arester kaskade.

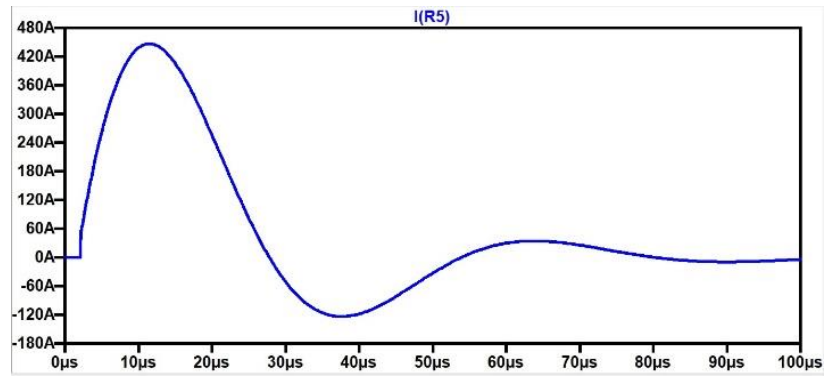

Gambar 9. Gelombang arus potong dari gas discharge tube (GDT) arrester

Bentuk gelombang arus potong gas discharge tube arrester (GDT) ditunjukkan pada gambar 9. Sedangkan gambar 10 menunjukkan gelombang tegangan naik (spark-over) 920 $\mathrm{V}$ dan mengalami arc region menuju nol volt pada waktu $2 \mu$ s. Ketika GDT berada pada kondisi spark-over hingga arc region tidak ada arus yang mengalir. Gelombang arus 
mulai naik hingga 450 A ketika gelombang tegangan turun pada nol volt.

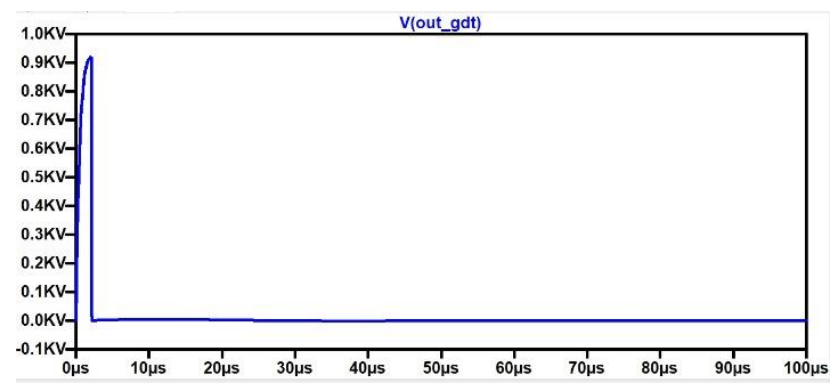

Gambar 10. Gelombang Tegangan Potong dari gas discharge tube (GDT) arrester

\subsection{Kaskade dengan Dekopling Induktor $1 \mathrm{mH}$}

Gambar 11 di bawah merupakan arus dan tegangan output MOV dengan nilai dekopling induktor $1 \mathrm{mH}$. MOV memotong tegangan di $200 \mathrm{~V}$ dan arus yang melalui MOV sebesar $720 \mathrm{~mA}$. GDT masih konduksi selama $4 \mu \mathrm{s}$ selama transien hingga akhirnya padam dan siap untuk transien berikutnya.

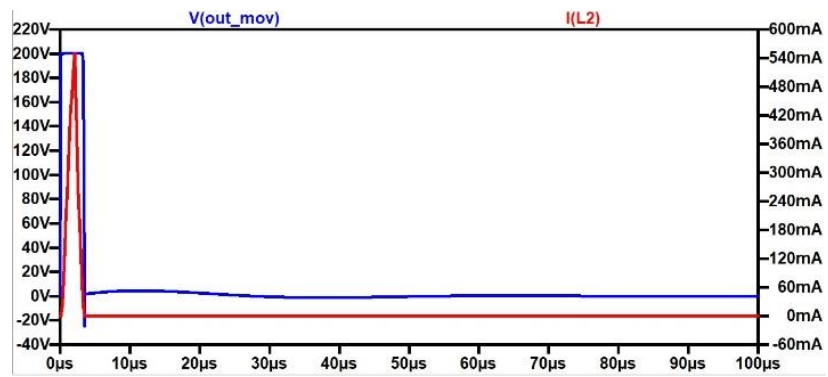

\section{Gambar 11. Arus Output MOV Dekopling Induktor} $1 \mathrm{mH}$

\subsection{Kaskade dengan Dekopling Induktor 1H}

Arus dan tegangan output MOV dengan nilai dekopling induktor $1 \mathrm{H}$ ditunjukkan pada gambar 12 di bawah ini.

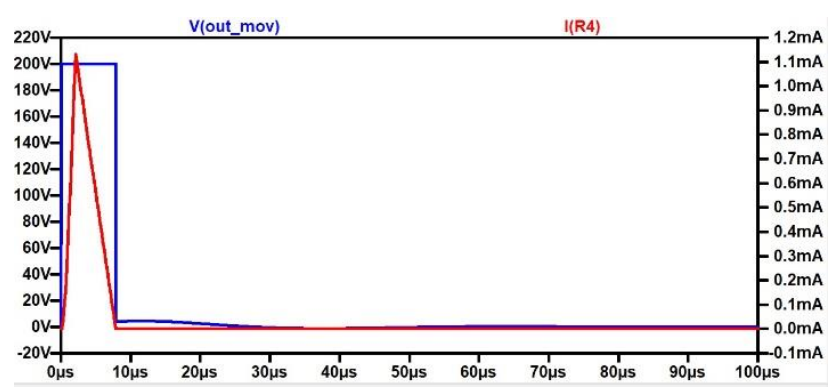

Gambar 12. Arus dan tegangan Output MOV
Dekopling Induktor 1H
MOV memotong tegangan pada $200 \mathrm{~V}$ dan arus yang melalui MOV sebesar 1,05 mA. GDT masih konduksi selama $8 \mu$ s selama transien hingga akhirnya padam dan siap untuk transien berikutnya.

\section{Kesimpulan}

Rangkaian arester kaskade telah dirangkaikan dengan pengujian surja menggunakan rangkaian generator impuls. Simulasi rangkaian pada LT Spice IV mampu merepresentasikan simulasi arus dan tegangan surja yang dihasilkan generator impuls dengan tegangan yang dihasilkan sebesar $920 \mathrm{~V}$ dan arus yang dihasilkan sebesar 470A. Simulasi LT Spice IV juga mampu merepresentasikan rangkaian arester kaskade dengan dekopling. Arester kaskade pada rangkaian menggunakan komponen terbaik. Komponen arester GDT membuang energi besar dari gelombang surja. Tegangan spark-over yang melalui GDT kemudian mengalami arc region menuju nol volt pada waktu $2 \mu \mathrm{s}$. MOV memiliki kecepatan operasi dan pemotongan surja yang akurasi. Terlihat dari hasil pengujian, GDT konduksi selama $4 \mu \mathrm{s}$ dan $8 \mu$ s selama transien dengan dua nilai dekopling induktor yang berbeda. Nilai dekopling induktor berpengaruh dalam distribusi energi arester kaskade GDT dan MOV. Peningkatan nilai dekopling induktor menyebabkan penurunan nilai arus di MOV sehingga energi yang menuju peralatan yang diproteksi lebih rendah. Peningkatan nilai dekopling induktor memberikan distribusi energi yang tepat antara arester GDT dan MOV.

\section{Referensi}

[1]. B. J. Jun and G. Z. Hua, "Energy coordination to the terminal device with built-in varistor," 20117 th AsiaPacific Int. Conf. Light. APL2011, pp. 125-130, 2011.

[2]. M. A. Uman, The art and science of lightning protection. 2008.

[3]. M. Hodžić, A. Mujčić, N. Suljanović, and M. Zajc, "Modelling Overvoltage Protection Components: Verilog Simulations of Combined MOV and GDT Arresters," Inf. MIDEM, vol. 47, no. 4, pp. 261-271, 2017.

[4]. V. Radulovic, S. Mujovic, and Z. Miljanic, "Effects of Different Combination Wave Generator Design on Surge Protective Devices Characteristics in Cascade Protection Systems," IEEE Trans. Electromagn. Compat., vol. 59, no. 3, pp. 823-834, 2017.

[5]. D. Kladar and F. Martzloff, "Facts, fiction, and fallacies in SPD design and applications," 2006 IEEE Power Eng. Soc. Gen. Meet., p. 8 pp., 2006.

[6]. Z. He and Y. Du, "SPD protection distances to household appliances connected in parallel," IEEE Trans. Electromagn. Compat., vol. 56, no. 6, pp. 1377-1385A, 2014.

[7]. S. Wang and J. He, "Discussion on worst distance between spd and protected device," IEEE Trans. Electromagn. Compat., vol. 53, no. 4, pp. 1081-1083, 2011.

[8]. C. Li et al., "Effective protection distances of SPDs for household electrical appliances," IEEE Trans. 
Electromagn. Compat., vol. 53, no. 3, pp. 690-699, 2011.

[9]. Jinliang He, Zhiyong Yuan, Shunchao Wang, Jun Hu, Shuiming Chen, and Rong Zeng, "Effective Protection Distances of Low-Voltage SPD With Different Voltage Protection Levels," IEEE Trans. Power Deliv., vol. 25, no. 1, pp. 187-195, 2009.

[10]. H. Kijima and K. Murakawa, "Lightning Surge Response Improvement by Combinations of Varistors and Gas Discharge Tubes 1 Introduction Problems in the case of using a varistor and a GDT," vol. 7, no. 2, pp. 60-69, 2012 .

[11]. J. Ribic, J. Vorsic, and J. Pihler, "Mathematical model of a gas discharge arrester based on physical parameters," IEEE Trans. Power Deliv., vol. 29, no. 3, pp. 985-992, 2014.

[12]. M. Bizjak, M. Bekovic, and A. Hamler, "Spark breakdown in gas-discharge-tube surge arrester at voltage pulse," IEEE Trans. Power Deliv., vol. 30, no. 3, pp. 1552-1560, 2015.
[13]. E. Society, IEEE Guide for the Application of SurgeProtective Components in Surge Protective Devices and Equipment Ports - Part 1 : Gas Discharge Tubes (GDTs ) IEEE Power and Energy Society IEEE Guide for the Application of Surge-Protective Components in Surge Protective Devices and Equipment Ports - Part 1: Gas Discharge Tubes (GDTs ). 2016.

[14]. V. Ngampradit, "Discussion on measured impulse sparkover voltage of Gas Discharge Tubes (GDT)," 2010 30th Int. Conf. Light. Prot. ICLP 2010, vol. 2010, pp. 19, 2017.

[15]. E. Kuffel, W. S. Zaengl, and J. Kuffel, "High Voltage Engineering," in High Voltage Engineering Fundamentals, 2000, p. 534.

[16]. S. Davis, Power Management. Penton Media, Inc, 2016.

[17]. P. D. A. Arismunandar, Teknik Tegangan Tinggi, Cetakan Ke. Jakarta: PT. Pertja, 2001. 